\title{
Global equity in protection of pregnant frontline workers
}

\section{[version 1; peer review: 2 approved with reservations]}

\author{
Elana F. Jaffe (D1,2, Ruth A. Karron3,4, Carleigh B. Krubiner5,6, Chizoba B. Wonodi3, \\ Richard H. Beigi ${ }^{7}$, Jeanne S. Sheffield ${ }^{4}$, Ruth R. Faden ${ }^{6,8}$ \\ ${ }^{1}$ Social Medicine, University of North Carolina at Chapel Hill, Chapel Hill, North Carolina, 27599, USA \\ 2Maternal, Child, and Family Health, University of North Carolina at Chapel Hill, Chapel Hill, North Carolina, 27599, USA \\ 3International Health, Johns Hopkins Bloomberg School of Public Health, Baltimore, Maryland, 21205, USA \\ 4Johns Hopkins Medicine, Baltimore, Maryland, 21205, USA \\ ${ }^{5}$ Center for Global Development, Washington, DC, USA \\ 6 Johns Hopkins Berman Institute of Bioethics, Baltimore, Maryland, 21205, USA \\ ${ }^{7}$ Magee Womens Hospital of UPMC, Pittsburgh, Pennsylvania, USA \\ ${ }^{8}$ Health Policy and Management, Johns Hopkins Bloomberg School of Public Health, Baltimore, Maryland, 21205, USA
}

V1 First published: 26 Mar 2021, 6:66

https://doi.org/10.12688/wellcomeopenres.16548.1

Latest published: 26 Mar 2021, 6:66

https://doi.org/10.12688/wellcomeopenres.16548.1
Open Peer Review

\begin{tabular}{ccc} 
Approval Status & $? ?$ \\
& 1 & 2 \\
\hdashline & $?$ & $?$ \\
version 1 & $?$ & view \\
\hline 2 Mar 2021 & view &
\end{tabular}

1. Erkan Kalafat, Koç University, Istanbul,

Turkey

2. Angela Ballantyne, University of Otago,

Wellington, New Zealand

Any reports and responses or comments on the article can be found at the end of the article. 
and serving on the frontlines of the pandemic will require no less.

Keywords

COVID-19, Vaccines, Pregnancy, Essential workers, Frontline workers

Q. This article is included in the Coronavirus

(COVID-19) collection.

Corresponding author: Elana F. Jaffe (elana_jaffe@med.unc.edu)

Author roles: Jaffe EF: Conceptualization, Writing - Original Draft Preparation, Writing - Review \& Editing; Karron RA:

Conceptualization, Writing - Review \& Editing; Krubiner CB: Conceptualization, Writing - Review \& Editing; Wonodi CB:

Conceptualization, Writing - Review \& Editing; Beigi RH: Writing - Review \& Editing; Sheffield JS: Writing - Review \& Editing; Faden RR:

Conceptualization, Writing - Original Draft Preparation, Writing - Review \& Editing

Competing interests: No competing interests were disclosed.

Grant information: This work is supported by Wellcome [221556, https://doi.org/10.35802/221556].

The funders had no role in study design, data collection and analysis, decision to publish, or preparation of the manuscript.

Copyright: @ $2021 \mathrm{Jaffe}$ EF et al. This is an open access article distributed under the terms of the Creative Commons Attribution License, which permits unrestricted use, distribution, and reproduction in any medium, provided the original work is properly cited.

How to cite this article: Jaffe EF, Karron RA, Krubiner CB et al. Global equity in protection of pregnant frontline workers [version 1; peer review: 2 approved with reservations] Wellcome Open Research 2021, 6:66 https://doi.org/10.12688/wellcomeopenres.16548.1

First published: 26 Mar 2021, 6:66 https://doi.org/10.12688/wellcomeopenres.16548.1 


\section{Disclaimer}

The views expressed in this article are those of the author(s). Publication in Wellcome Open Research does not imply endorsement by Wellcome.

\section{Introduction}

At any given time, around 200 million people in the world are pregnant, and many of them serve on the pandemic frontlines ${ }^{1,2}$. Highly effective COVID-19 vaccines are currently being offered to frontline health workers and other prioritized groups in some settings. Globally, women comprise $70 \%$ of the health workforce, and are heavily represented in other frontline occupations, most notably education ${ }^{2}$. However, faced with limited pregnancy-specific data, various national public health agencies have responded differently to the use of COVID-19 vaccines in pregnancy. For example, in the United States (US) and Canada, pregnant people are eligible to receive COVID-19 vaccines, but in other countries, including Chile and Singapore, pregnant people are being denied access to these same vaccine products ${ }^{3-6}$. This problematic disjunct in policy is the result of a lack of expediency in gathering pregnancy-specific data for COVID-19 vaccines.

As additional countries evaluate their policy on pregnancy and newly authorized vaccines, we present three actionable recommendations to achieve equitable protection of pregnant frontline workers. First, for the COVID-19 vaccines already authorized, additional evidence must be collected and analyzed as soon as possible. This evidence must be sufficient to support an explicitly positive or negative recommendation for use in pregnancy, rather than a permissive policy or blanket exclusion. Such evidence can also support efforts to harmonize conflicting international recommendations. Second, for COVID-19 vaccines still in development, investments must be made now to reduce the lag time between authorization for the general public and recommendations for use in pregnancy. Third, pregnant frontline workers who are denied access to COVID-19 vaccines, or who decline vaccination due to a lack of pregnancy-specific evidence, should be prioritized for alternate protective measures and, if necessary, therapeutic interventions.

\section{Recommendations}

1. Ensure evidence for explicit recommendation around authorized COVID-19 vaccine use in pregnancy

Regulatory and public health authorities considered the Pfizer/ BioNTech, Moderna, Janssen, and AstraZeneca vaccines in pregnancy under conditions of significant empirical uncertainty. In some cases, not even pre-clinical data from developmental and reproductive toxicology studies were available at time of regulatory evaluation. Decision-making groups had to take a position based largely on scientific judgments about the biological plausibility of risks of these vaccines to pregnant people and their offspring, the risks of COVID-19 infection in pregnancy, and the remarkable efficacy of these vaccines for prevention of any COVID-19 disease, severe disease, and death. Pregnancy is a risk factor for severe COVID-19, with data from the US suggesting that pregnant people are three times more likely to require intensive care and $70 \%$ more likely to die when compared with non-pregnant peers ${ }^{7}$. Based on experience with other vaccines, currently authorized COVID-19 vaccines are expected to be as efficacious in pregnant people as in other adults.

Because of the significant risks of infection and serious COVID-19 disease that some pregnant frontline workers face, the permissive position taken by the US and Canada is ethically preferable. But permissive recommendations for use of these vaccines in pregnancy are ultimately insufficient. Leaving decision-making to pregnant frontline workers in consultation with their individual providers without an explicit positive recommendation puts many pregnant frontline workers in a potentially difficult position. They now shoulder the burden of having to navigate complex, technical, and most critically, limited evidence. Shifting the locus of decision-making to pregnant frontline workers increases the likelihood that decisions might suffer from bias by well-established risk distortions around interventions in pregnancy $^{8}$. At a minimum, when pregnant frontline workers are offered vaccine, they should also be provided curated up-to-date information about the specific vaccine in pregnancy and where possible, an opportunity to discuss the decision with an obstetrical provider ${ }^{9,10}$. As many country policies also relegate decision-making about vaccination to the clinical-context, ensuring broad provider education about the risks and benefits of COVID-19 vaccines in pregnancy will be paramount to ensure equitable access.

As vaccine eligibility expands, there will be many more pregnant people who will soon be faced with the dilemma of evaluating risks and benefits for themselves and their developing fetus. And as vaccines becomes available to the general population, the unfair burden on individual pregnant people making this decision will exponentially expand. There is an opportunity to minimize the unfairness to pregnant people, if action is taken in the near term. All pregnant people who choose to be vaccinated should be able to enroll in well-designed pregnancy registries or prospective observational studies. Thus far only Pfizer BioNTech has begun enrollment in a pregnancy-specific randomized control trial. As more such studies are designed, conversations between sponsors, regulators, advisory committees, and public health authorities should determine the specific evidence that would be required for an explicit recommendation for use in pregnancy.

\section{Avoid delays in pregnancy-specific data for COVID-19} vaccines currently in development

Efforts to collect prospective observational data on pregnant workers vaccinated in countries where vaccines are being offered in pregnancy will provide valuable information for vaccination of other pregnant populations, but this data will only pertain to the specific vaccine products deployed. Other COVID-19 vaccine products brought to market may have different safety and efficacy profiles that bear on their suitability for use in pregnancy, in part dependent on the platform they use. Among the COVID-19 vaccine candidates currently in Phase 3 trials, a wide range of different platforms are represented, including viral vector platforms, inactivated virus platforms, and protein subunit platforms ${ }^{11}$. Given different levels of experience with each of these platforms in pregnancy, the data needed to support an explicit recommendation around use in pregnancy may vary between platforms. 
Where completed DART studies are needed, results should be provided at time of request for emergency authorization. When requesting emergency authorization, investigators and sponsors should also supply any data from incident pregnancies among trial participants and a timetable for providing the results of studies underway or planned with pregnant people. For all vaccines in development, plans should be solidified now that specify what preclinical and clinical pregnancy-specific data should be collected, and when, to narrow and ideally close the gap between the time of request for emergency use authorization in adults and when a recommendation for use in pregnant people can be provided. These plans should be developed in discussions between regulatory authorities, relevant advisory bodies, technical experts, policymakers, vaccine developers, and sponsors and should be communicated to the public.

Because evidence that pregnancy is a risk factor for severe COVID-19 disease comes primarily from $\mathrm{HIC}^{7,12-16}$, regulatory bodies in LMIC face an additional challenge. Additional vaccine data on the safety and efficacy in pregnancy will likely strengthen regulators' positions in low-resource settings to make timely and clear recommendations on the vaccine use in pregnancy and avoid unfair delays or denials of vaccine access to pregnant frontline workers in these contexts.

\section{Prioritize pregnant frontline workers who are denied or who decline COVID-19 vaccines for alternative protection}

A decision, such as the one taken by public health authorities in Chile and Singapore, to exclude pregnant people from accessing COVID-19 vaccines offered to their non-pregnant co-workers does not relieve policy makers of ethical obligations to pregnant essential workers. A no-vaccine policy for pregnant workers should not mean a no-protection policy. Additionally, because the evidence to support COVID-19 vaccination in pregnancy is less complete than for the general population, pregnant frontline workers should be allowed to decline vaccination and be afforded priority protection.

Especially in times of high demand for health and other essential services, employers will need to think creatively about how to balance three potentially competing priorities: accommodating pregnant workers' needs and desires to work and continue receiving compensation, ensuring capacity to care for surges in demand, and mitigating risk to their pregnant workers. Wherever possible, pregnant workers who are not vaccinated should be offered the opportunity to transfer to low-risk settings or roles. Unvaccinated pregnant workers who cannot be reassigned to low-risk settings or roles should be permitted to take leave when institutionally feasible without jeopardizing employment security and, if possible, with pay. Parental leave policies should remain unaffected. Additionally, unvaccinated pregnant frontline workers should be prioritized for preferential access to personal protective equipment or treatments that may be rationed due to short supply.

\section{Conclusion}

Crafting ethically acceptable policies for protecting pregnant frontline workers as COVID-19 vaccines are rolled out globally is a complex, dynamic, and context-dependent process. Because of the medical and ethical complexities of assessing risk and prospect for benefit across the trimesters of pregnancy, it is imperative that this determination be guided by experts in maternal-fetal medicine, pediatrics, and obstetrics who are knowledgeable about infectious disease and vaccinology, as well experts in bioethics and pregnant workers or their representatives. These experts and stakeholders deliberating together will be best positioned to guide decision-makers in finding an ethically acceptable policy option.

Pregnant workers face compounded risks from occupational exposure and heightened risk from infection in pregnancy. They are also simultaneously disadvantaged by the current failure to focus on pregnancy in evidence generation for both COVID-19 vaccines and therapeutics ${ }^{17,18}$. It is critical that the COVID-19 research and development enterprise work to fill the evidence gap that is so detrimental to pregnant people and their offspring, as a matter of health equity and public health. Until there is evidence to support explicit recommendations for COVID-19 vaccination in pregnancy, objectives to protect the frontline workforce will fall short.

\section{Data availability}

No data is associated with this work.
1. Boniol M, McIsaac M, Xu L, et al.: Gender equity in the health workforce: Analysis of 104 countries. World Health Organization, 2019. Reference Source

2. International Labour Office: World Employment and Social Outlook: Trends for women 2017. Geneva: ILO, 2017. Reference Source

3. Instituto de Salud Publico Chile, Ministerio de Salud: Ficha Informativa de Vacuna: Vacuna COVID-19 Pfizer-BioNTech. 2020. Reference Source

4. Advisory Committee on Immunization Practices Emergency Meeting. 2020. Reference Source
5. Health Canada: Pfizer-BioNTech COVID-19 Vaccine [COVID-19 mRNA Vaccine] Product Monograph. 2020. Reference Source

6. Ministry of Health Singapore. COVID-19 Vaccination Programme. 2021. Reference Source

7. Zambrano LD, Ellington S, Strid P, et al.: Update: characteristics of symptomatic women of reproductive age with laboratory-confirmed SARSCoV-2 infection by pregnancy status - United States, January 22-October 3 , 2020. MMWR Morb Mortal Wkly Rep. 2020; 69(44): 1641-1647. PubMed Abstract | Publisher Full Text | Free Full Text

8. Lyerly $A D$, Mitchell $L M$, Armstrong EM, et al.: Risk and the pregnant body. 
Hastings Cent Rep. 2009; 39(6): 34-42.

PubMed Abstract | Publisher Full Text | Free Full Text

9. American College of Obstetricians and Gynecologists' Immunization, Infectious Disease, and Public Health Preparedness Expert Work Group: Practice advisory: vaccinating pregnant and lactating patients against COVID-19. 2020.

Reference Source

10. Society for Maternal Fetal Medicine: Pregnant Persons: What should be considered when counseling a pregnant person regarding COVID-19 vaccination? 2020.

11. London School of Hygiene \& Tropical Medicine: COVID-19 vaccine tracker. Accessed December 28, 2020. Reference Source

12. Delahoy MJ, Whitaker M, O'Halloran A, et al.: Characteristics and maternal and birth outcomes of hospitalized pregnant women with laboratoryconfirmed COVID-19 - COVID-NET, 13 States, March 1-August 22, 2020. MMWR Morb Mortal Wkly Rep. 2020; 69(38): 1347-1354. PubMed Abstract | Publisher Full Text | Free Full Text

13. Ellington $S$, Strid $P$, Tong VT, et al.: Characteristics of women of reproductive age with laboratory-confirmed SARS-CoV-2 infection by pregnancy status - United States, January 22-June 7, 2020. MMWR Morb Mortal Wkly Rep. 2020;
69(25): 769-775

PubMed Abstract | Publisher Full Text | Free Full Text

14. Dashraath P, Wong JLJ, Lim MXK, et al.: Coronavirus disease 2019 (COVID-19) pandemic and pregnancy. Am J Obstet Gynecol. 2020; 222(6): 521-531. PubMed Abstract | Publisher Full Text | Free Full Text

15. Kucirka LM, Norton A, Sheffield JS: Severity of COVID-19 in pregnancy: A review of current evidence. Am J Reprod Immunol. 2020; 84(5): e13332. PubMed Abstract | Publisher Full Text

16. Panagiotakopoulos L, Myers TR, Gee J, et al.: SARS-CoV-2 infection among hospitalized pregnant women: reasons for admission and pregnancy characteristics - eight U.S. health care centers, March 1-May 30, 2020. MMWR Morb Mortal Wkly Rep. 2020; 69(38): 1355-1359. PubMed Abstract | Publisher Full Text | Free Full Text

17. Pastick KA, Nicol MR, Smyth E, et al.: A systematic review of treatment and outcomes of pregnant women with COVID-19-a call for clinical trials. Open Forum Infect Dis. 2020; 7(9): ofaa350. Forum Infect Dis. 2020; 7(9): Ofaa350.
PubMed Abstract | Publisher Full Text | Free Full Text

18. Riley LE, Hughes BL: Pregnancy should not exclude women from Covid-19 trials. STAT. 2020; Accessed September 29, 2020.

Reference Source 


\title{
Open Peer Review
}

\section{Current Peer Review Status: ? ?}

\section{Version 1}

Reviewer Report 16 May 2022

https://doi.org/10.21956/wellcomeopenres.18234.r50021

(C) 2022 Ballantyne A. This is an open access peer review report distributed under the terms of the Creative Commons Attribution License, which permits unrestricted use, distribution, and reproduction in any medium, provided the original work is properly cited.

\author{
Angela Ballantyne \\ Department of Primary Health Care \& General Practice, University of Otago, Wellington, New \\ Zealand
}

It is a well-research and well-argued paper that raises important issues regarding the relationship between research and safe and effective clinical care for pregnant women. Given the covid pandemic has developed rapidly, the core target of the authors' argument (countries limiting access to the covid vaccine for pregnant women) is now out of date. I am not aware of any country that currently prohibits the vaccination of pregnant women. The authors cite Chile, Singapore, and Canada but all of these countries now allow vaccination of pregnant women.

As of 2021, Chile has prioritized pregnant women for COVID-19 vaccination. Singapore, as of 2021, encouraged vaccination of pregnant women at any point in the pregnancy. This recent analysis suggests the current problem is slow uptake for pregnant women, rather than prohibition https://www.nature.com/articles/d41586-022-00031-8 Can the argument be refocused for the current context?

Understandably, some of the empirical data is also now out of date - it would be helpful to include more up to date information regarding pregnancy risk due to covid?

I have said the paper does not "adequately reference differing views and opinions". This is because the paper argues for an 'ethical' vaccine policy but does not describe which ethical principles or values would support priority vaccine access for frontline pregnant workers reciprocity (because they are frontline workers?), equity (because it is unjust to deny access to pregnant women - if anyone still is denying access?), protecting the worst-off (because pregnant women are at higher risk?). A short paragraph on the ethical foundation for the argument would greatly increase the value of the paper.

Is the rationale for the Open Letter provided in sufficient detail? Yes

Does the article adequately reference differing views and opinions? 
No

Are all factual statements correct, and are statements and arguments made adequately supported by citations?

No

Is the Open Letter written in accessible language?

Yes

Where applicable, are recommendations and next steps explained clearly for others to follow?

Yes

Competing Interests: No competing interests were disclosed.

Reviewer Expertise: Bioethics, research ethics, the ethics of research with pregnant women, equity in relation to covid policies.

I confirm that I have read this submission and believe that I have an appropriate level of expertise to confirm that it is of an acceptable scientific standard, however I have significant reservations, as outlined above.

Reviewer Report 16 June 2021

https://doi.org/10.21956/wellcomeopenres.18234.r44475

(C) 2021 Kalafat E. This is an open access peer review report distributed under the terms of the Creative Commons Attribution License, which permits unrestricted use, distribution, and reproduction in any medium, provided the original work is properly cited.

\section{Erkan Kalafat}

Department of Obstetrics and Gynecology, School of Medicine, Koç University, Istanbul, Turkey

"For example, in the United States (US) and Canada, pregnant people are eligible to receive COVID-19 vaccines, but in other countries, including Chile and Singapore, pregnant people are being denied access to these same vaccine products ${ }^{3-6}$."

The reference includes Canada where I believe pregnant individuals are allowed to be vaccinated. Singapore would be a fringe example but looking at the website, even they seem to allow vaccination of pregnant individuals. Could authors cite more concrete examples of settings, where pregnant women are denied vaccination?

"Pregnancy is a risk factor for severe COVID-19, with data from the US suggesting that pregnant people are three times more likely to require intensive care and $70 \%$ more likely to die when compared with non-pregnant peers" 
The data from Zambrano is probably an overestimate of the actual risk increase. The denominator in the data is symptomatic infections and pregnant women have lower odds of symptomatic infection. Moreover, the relative risk increase looks more sensational while the absolute risk increase corresponds to 3 per 10.000 symptomatic infections. I know it is nitpicking but not quoting precise risk estimates may be better (i.e., at increased risk).

The situation in LMIC setting may be slightly different than what has been described in the letter. It is true that reports from LMIC settings are lacking but the synthesis of the available body of evidence shows they are disproportionally affected. ${ }^{1}$ Moreover, pregnant women in LMICs, where the pandemic has been especially disastrous, want to get vaccinated with very low levels of vaccine hesitancy. ${ }^{2}$ I think lack of access to vaccines is a more important issue for such settings rather than regulatory agencies prohibiting vaccination for pregnant women. Most LMICs have limited access to vaccination while some south African countries have virtually no access. Although I agree with the overarching message that delays should be avoided, it does not really fit into the scenario for LMICs.

Finally, the last update from CDC is almost two months old. ${ }^{3}$ MHRA did not report any official statistics as far as I am aware. Perhaps more emphasis can be put into the letter about the poor performance of regulatory agencies on this topic.

Other comments

I think one of the most interesting points of this letter is the ethical ambiguity of leaving the responsibility to physicians and patients. I see one of the authors is a distinguished Professor of Bioethics. It would have been nice to read more arguments on the issue.

While proposed actions are logical, some countries have already implemented such measures. None of these examples are mentioned in the letter.

\section{References}

1. Chmielewska B, Barratt I, Townsend R, Kalafat E, et al.: Effects of the COVID-19 pandemic on maternal and perinatal outcomes: a systematic review and meta-analysis. The Lancet Global Health. 2021; 9 (6): e759-e772 Publisher Full Text

2. Skjefte M, Ngirbabul M, Akeju O, Escudero D, et al.: COVID-19 vaccine acceptance among pregnant women and mothers of young children: results of a survey in 16 countries.Eur J Epidemiol . 2021; 36 (2): 197-211 PubMed Abstract | Publisher Full Text

3. Shimabukuro TT, Kim SY, Myers TR, Moro PL, et al.: Preliminary Findings of mRNA Covid-19

Vaccine Safety in Pregnant Persons.N Engl J Med. 2021. PubMed Abstract | Publisher Full Text

\section{Is the rationale for the Open Letter provided in sufficient detail?}

Yes

Does the article adequately reference differing views and opinions?

Partly

Are all factual statements correct, and are statements and arguments made adequately supported by citations? 
Yes

Is the Open Letter written in accessible language?

Yes

Where applicable, are recommendations and next steps explained clearly for others to follow?

Not applicable

Competing Interests: No competing interests were disclosed.

Reviewer Expertise: COVID-19 and pregnancy

I confirm that I have read this submission and believe that I have an appropriate level of expertise to confirm that it is of an acceptable scientific standard, however I have significant reservations, as outlined above. 